\title{
55013 BIOFILTRATION OF VOLATILE POLLUTANTS: Fundamental Mechanisms for Improved Design, Long-term Operation, Prediction, and Implementation
}

\author{
Publication Date: March 1, 2000
}

Lead Principal Investigator:
Brian H. Davison, Ph.D.

Oak Ridge National Laboratory

P.O. Box 2008

Oak Ridge, TN 37831-6226

davisonbh@ornl.gov

(423) 576-8522

fax (423) $574-6442$

\author{
Co-Investigators: $\quad$ K. Thomas Klasson, Ph.D. \\ John W. Barton, Ph.D. \\ Oak Ridge National Laboratory \\ Oak Ridge National Laboratory \\ P.O. Box 2008 P.O. Box 2008 \\ Oak Ridge, TN 37831-6044 \\ klassonkt@ornl.gov \\ (423) 574-6813 (423) 241-5706 \\ fax (423) $576-4195$ \\ Oak Ridge, TN 37831-6044 \\ bartonjw@ornl.gov \\ fax (423) 576-4195
}

\begin{abstract}
Graduate Students: Gregory Clark Delozier received his Masters of Science in Biotechnology from University of Tennessee (December, 1998); his thesis work involved DNA-typing and isolation of the bacterial species responsible for degradation of VOCs in the columns used in the experiments on this project.
\end{abstract}

Research Objective. Biofiltration systems can be used for treatment of volatile organic compounds (VOCs); however, the systems are poorly understood and are currently operated as "black boxes". Common operational problems associated with biofilters include fouling, deactivation, and overgrowth, all of which make them ineffective for continuous, long-term use. The objective of this investigation is to develop generic methods for long-term stable operation, in particular by using selective limitation of supplemental nutrients while maintaining high activity. As part of this effort, we will provide deeper fundamental understanding of the important biological and transport mechanisms in biodestruction of sparingly soluble VOCs and extend this approach and mathematical models to additional systems of high priority EM relevance - direct degradation and cometabolic degradation of priority pollutants such as BTEX and chlorinated organics.

Research Progress and Implications. This report summarizes progress during the third year of a 3-year project. Major results are enumerated and discussed below.

1. A manuscript detailing how to control biofilm overgrowth, while sustaining high degradation rates, in operating trickle-bed bioreactors has been submitted for publication. Optimal results were achieved by limiting either ammonium, sulfate, or calcium in the liquid recycle stream. Each of these allowed for decoupling of growth and degradation such that long-term operation was possible. Other nutrients examined, including chlorine, magnesium, phosphate, and nitrate, were not effective and resulted in either continued growth or minimal degradation rates. These results are important for enabling longer term operation of traditional biofiltration units.

2. Further development of a comprehensive two-dimensional predictive model to elucidate mass transfer and kinetic limitations in these systems was made. This model can be extended to a variety of columnar biofiltration systems by changing appropriate parameters. This user-friendly model/program can be installed and run independently on any IBM-compatible personal computer using Microsoft Windows 95/98.

3. Fundamental measurements of Henry's law coefficients for a variety of sparingly soluble alkanes in biomass were made; results indicated that these compounds have substantially higher solubilities in aqueous biomass than in pure water (see Figure). Since predictive calculations for bioprocesses are strongly affected by the magnitude of the Henry's law parameters, new correlations/measurements are needed to compensate for this effect. These data could have a significant impact on current models being used for subsurface transport and clean up strategies. A proposal for follow-on/extension funding in this specific area is being submitted. 


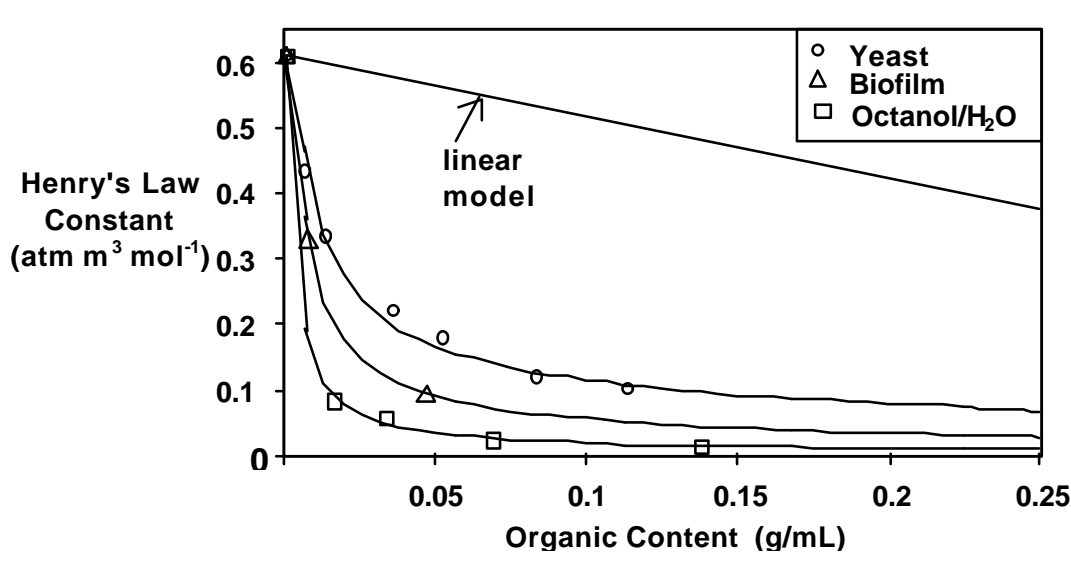

Figure. Unpublished preliminary data for propane which show deviation from ideal models of partitioning between biomass and gas phases (as would be likely in vadose zones and surface impoundments). Data were collected for yeast (circles) and bacteria (triangles) over a variety of organic densities and compared to two 'ideal models' for octanol/water partitioning (squares and straight line). In both cases, actual partitioning measurements deviated significantly from idealized models for pure water/octanol mixtures.

4. A manuscript detailing the effects of biomass on Henry's law constants has been accepted for publication in Biotechnology and Bioengineering.

5. Isolation of a microorganism capable of degrading a variety of VOC's and chloroorganics was completed. The organism was identified as a slow-growing, aerobic, gram-positive rod. By identifying the strain responsible, quick seeding of the biofilters is much simpler than using a mixed consortium. DNA typing is pending.

6. Kinetic factors associated with growth of the above-mentioned organism were quantified, including specific growth rate and saturation constant. These factors are useful in describing uptake and cell division in mathematical models.

7. Degradation of BTEX compounds in column biofiltration units was initiated this year.

8. Experiments designed to test alternative packing and 'seeding' strategies were initiated this year. These experiments examine new matrices for rapid bacterial adhesion/start-up and long-term stability.

PLANNED ACTIVITIES. Remaining activities:

1. Extension of the mathematical model to other biofiltration systems

2. Publication of the model/Windows 95 program code on the World Wide Web

3. Measurement of solubilities and Henry's law constants of critical contaminants (TCE, BTEX, etc.) in biomass.

INFORMATION ACCESS. A number of peer-reviewed publications have been submitted and/or accepted based on some of the results from this work. Several presentations at national scientific conferences have been given or are currently scheduled to be delivered during this calendar year. A complete list of submitted papers and presentations may be found below. More information is available at

$$
\text { http://www.etde.org/html/em52/55013.html }
$$

Peer-reviewed Publications during past year:

Davison, B.H., J.W. Barton, K.T. Klasson, A. F. Francisco. "Influence of Biomass on Alkane Solubilities" In press.

Francisco, A.F., J.W. Barton, K.T. Klasson, and B.H. Davison, "Nutrient Limitation Effects on a Microbial Consortium in Trickle-Bed Bioreactors," submitted for publication.

Klasson, K. T., J. W. Barton, and B. H. Davison. Performance of a Propane-degrading Bacterium. Proceedings of the $92^{\text {nd }}$ Annual Meeting of the Air and Waste Management Association, June 1999.

Barton, J. W., B. H. Davison, K. T. Klasson, and C. C. Gable III. Estimation of Mass Transfer and Kinetics in Operating Trickle-Bed Bioreactors for Removal of VOCs. Environ. Prog. 18:1-5, 1999.

Barton, J. W., X. S. Zhang, B. H. Davison, and K. T. Klasson. Predictive Mathematical Modeling of Trickling Bed Biofilters. Proceedings of the 1998 USC-TRG Conference on Biofiltration, October 22-23, Los Angeles, CA.

Barton, J. W., X. S. Zhang, K. T. Klasson, and B. H. Davison, Predictive Mathematical Modeling of Trickling Bed Biofilters for Elucidating Mass Transfer and Kinetic Effects, Proceedings of the $91^{\text {st }}$ Annual Meeting of the Air and Waste Management Association, San Diego, CA, June 1998. Paper 98-WAA.13P.

Klasson, K. T., B. H. Davison, J W. Barton and J. E. Jacobs, Removal of Chlorinated and Nonchlorinated Alkanes in a Trickling Bed Biofilter, Proceedings of the $91^{\text {st }}$ Annual Meeting of the Air and Waste Management Association, San Diego, CA, June 1998. Paper 98-WAA.06P.

Barton, J. W., S. Hartz, K. T. Klasson, and B. H. Davison, Microbial Removal of Alkanes from Dilute Gaseous Waste Streams: Mathematical Modeling of Advanced Bioreactor Systems," J. Chem. Technol. Biotechnol. 72:93-98 (1998). 